\title{
Separación de subfamilias en la familia de chinches Gelastocoridae (Hemiptera)
}

\author{
Ana Lía Estévez \& Mónica L. López Ruf \\ Museo de La Plata, División Científica de Entomología. Paseo del Bosque B1900FWA La Plata, Argentina; \\ estevezanalia@hotmail.com; lopezruf@museo.fcnym.unlp.edu.ar
}

Recibido 28-XI-2003. C Corregido 27-VII-2005. Aceptado 02-VI-2006.

\begin{abstract}
Subfamily separation in the hemipteran family Gelastocoridae (Hemiptera). Gelastocoridae (Kirkaldy, 1897) has over 70 species in two subfamilies: Nerthrinae (Kirkaldy, 1898), genus Nerthra (Say, 1832) and Gelastocorinae (Champion, 1901), genus Gelastocoris (Kirkaldy, 1897). The position of the cephalic gland openings, presence and shape of the gular bridge and the number and position of abdominal spiracles, are presented as new morphologic diagnostic characteristics that support the argument used by Todd for the segregation of the subfamilies. The characteristics are described and illustrated on the basis of specimens from Laguna Iberá, Corrientes, Argentina. Rev. Biol. Trop. 54 (4): 1319-1322. Epub 2006 Dec. 15.
\end{abstract}

Key words: Heteroptera, Nerthrinae, Gelastocorinae, morphological characters.

La familia Gelastocoridae (Kirkaldy, 1897) incluye a más de 70 especies que se distribuyen en dos subfamilias: Nerthrinae (Kirkaldy, 1898), con solo el género Nerthra (Say, 1832), de distribución cosmopolita con alrededor de 60 especies descritas, y Gelastocorinae (Champion, 1901) también monotípica, de distribución americana e incluye a más de una docena de especies, pertenecientes al género Gelastocoris (Kirkaldy, 1897).

Los representantes de la familia son litorales y viven en las orillas de los cuerpos de agua. Las especies de Gelastocoris se han hallado siempre en el barro o en la arena en los márgenes de los arroyos y lagunas. Las especies de Nerthra se han hallado en ambientes similares, pero también en lugares alejados del agua (Todd 1955, Lauck y Wheatcroft 1958).

Las autoras de este trabajo han observado especímenes sumergidos de todos los estadios larvales y adultos de Nerthra ranina (Herrich-Schäffer), entre plantas arraigadas o desplazándose en el agua, ya sea caminando en el fondo o nadando en la superficie del agua reteniendo, en el área ventral, una burbuja de aire.

A ambas subfamilias se les distingue por las características del rostro, por la constitución del tarso del primer par de patas y por los últimos segmentos abdominales.

Gelastocoris presenta el rostro proyectado hacia abajo y cerca del ápex de la cabeza, el tarso del primer par de patas es unisegmentado y articulado, con dos uñas bien desarrolladas; los machos tienen el noveno segmento abdominal completamente invaginado en la sección ventral, no visible, en tanto que las hembras tienen los segmentos simétricos.

Nerthra tiene el rostro curvado hacia delante por debajo del ápex de la cabeza; el tarso del primer par de patas está fusionado con la tibia, no articulado y con una sola uña tarsal; el noveno segmento de los machos es visible y las hembras, según la especie, tienen los segmentos abdominales simétricos o asimétricos (Todd 1955). 
El propósito de este trabajo es dar a conocer nuevos caracteres diagnósticos para la determinación de las subfamilias de Gelastocoridae.

\section{MATERIALES Y MÉTODOS}

$N$. ranina se obtuvo en la laguna Iberá (prov. de Corrientes). La recolección se efectuó manualmente con la ayuda de coladores de nylon de trama fina (20 cm de diámetro), separando los individuos de entre las plantas acuáticas sumergidas, y fijándolos en alcohol al $70 \%$; se trabajaron en seco.

Para la primera limpieza de los ejemplares, se utilizó un tensioactivo no iónico con agregados de perborato, agentes alcalinos, enzimas, agentes blanqueadores y secuestrantes (nombre comercial: Sun). La mezcla se utilizó en agua caliente $\left(75^{\circ} \mathrm{C}\right)$ tres veces durante alrededor de 10 min cada vez. Seguidamente se colocó el material en una cubeta de vibración ultrasónica, sumergido en líquido limpiador (70 \% de alcohol etílico, $20 \%$ de acetato de etilo y $10 \%$ de benceno) durante $10 \mathrm{~min}$. Se enjuagó en alcohol $70 \%$ durante 5 min. Los ejemplares de montaron, se metalizaron con oro-paladio y se fotografiaron en un MEB Jeol T 100. Los dibujos esquemáticos se realizaron con cámara clara en microscopio estereoscópico.

Material examinado: Argentina, Corrientes, Reserva Provincial Iberá, laguna Iberá, 5708’20” S, 28²9’31” W, 2327/III/2002, N. ranina (Herrich-Schäffer): tres machos y cinco hembras, leg. Estévez y López Ruf; Argentina, Neuquén, Aluminé, 20/I/1958, N. quinquedentata (Melin): tres machos y tres hembras, leg. Bachmann; Brasil, Distrito Federal de Río de Janeiro, X/1931, N. terrestris (Kevan): una hembra; Bolivia, Cochabamba, Prov. Carrasco, Sehuencas, 2100 msnm, II/1962, N. amplicollis (Stål): una hembra; Chile, Valparaíso, 12/IX/1939, N. parvula Signoret: una hembra, leg. E.P. Reed; Brasil, Santa Catarina, Campos Novos, IV/1958, Gelastocoris monrosi De Carlo: dos machos, leg. Plaumann; Venezuela, Barinitas, XII/1942,
G. hungerfordi Melin: dos machos, leg. P. Anduze; Venezuela, Barinitas, XII/1942, G. major Montd.: una hembra, ex-coll. C.J. Drake, 1956, leg. P. Anduze; Perú, Dep. Huánuco, Cucharas, VIII/1954, G. bolivianus De Carlo: una hembra, ex-coll. C.J. Drake, 1956.

Salvo los ejemplares de $N$. ranina que se utilizaron para el MEB, los de las demás especies pertenecen al Museo Argentino de Ciencias Naturales “Bernadino Rivadavia”. Se ha utilizado la nomenclatura de Parsons (1959).

\section{RESULTADOS}

\section{Gelastocoris}

Se observó que la burbuja, durante la inmersión es continua entre las siguientes estructuras: las antenas, el área ventral de la cabeza por debajo de los ojos, entre los segmentos torácicos a la altura de las coxas y hasta el IV segmento abdominal. Los orificios de las glándulas cefálicas se encuentran a los lados de la cápsula cefálica, ventralmente, delante y muy cercanos a las bases de las antenas (Fig. 1). La abertura de la glándula está oculta entre repliegues del tegumento que está cubierto por pelos largos (Fig. 2). Área gular amplia (Fig. 1). Los espiráculos abdominales III y IV están desplazados hacia la línea media, ubicados en el borde de la concavidad que retiene la burbuja, que alcanza el IV segmento abdominal. Los espiráculos V y VI son laterales (Fig. 3).

\section{Nerthra}

Se observó que la burbuja, durante la inmersión, está retenida entre las antenas y el área ventral de la cabeza debajo de los ojos, en una concavidad de los segmentos torácicos que llega hasta el III segmento abdominal. Los orificios de las glándulas cefálicas se encuentran dorsolateralmente, sobre el tercio anterior de la sutura clípeo-maxilar (Fig. 4), ocultas entre varios repliegues del tegumento (Fig. 5). Área gular angosta (Fig. 6). Los espiráculos abdominales III al V se encuentran en posición lateral 


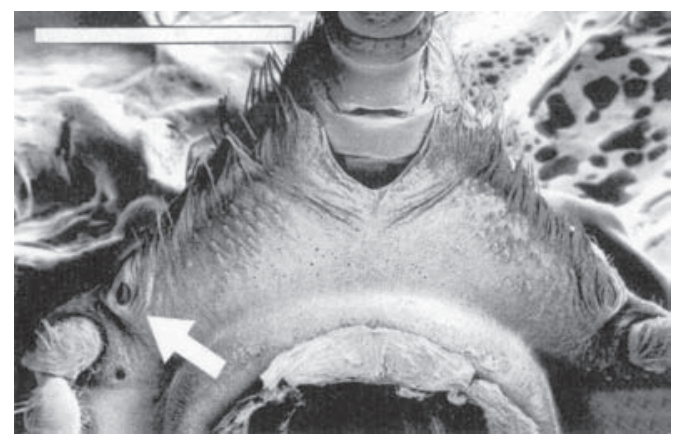

Fig. 1. Gelastocoris cápsula cefálica (glándula cefálica y gula). Esc.: $1 \mathrm{~mm}$.

Fig. 1. Gelastocoris cephalic capsule (cephalic gland and gula). Sca.: $1 \mathrm{~mm}$.

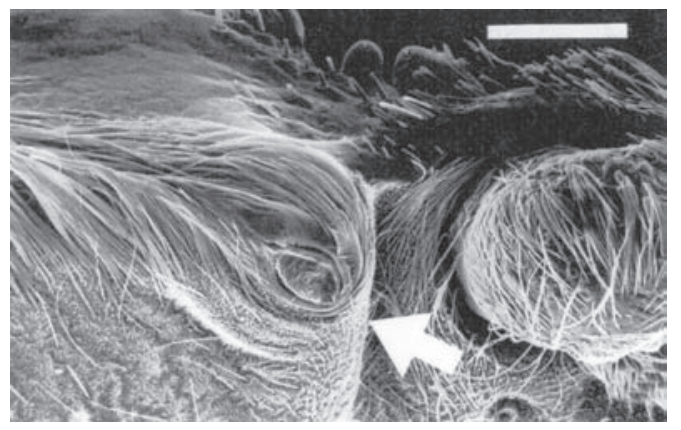

Fig. 2. Gelastocoris, abertura de la glándula cefálica. Esc.: $1 \mathrm{~mm}$.

Fig. 2. Gelastocoris, cephalic gland opening. Sca.: $1 \mathrm{~mm}$.

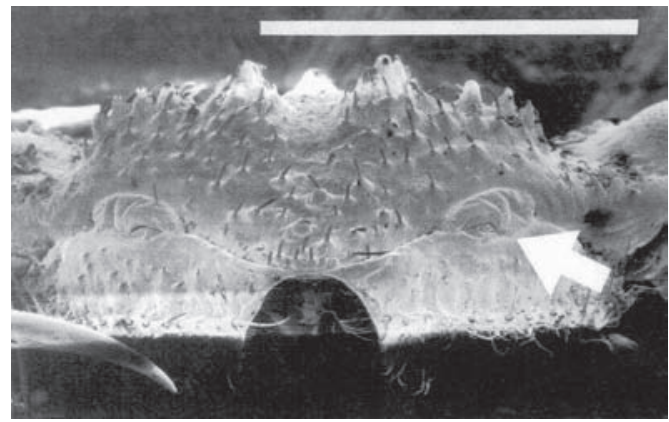

Fig. 4. Nerthra, cápsula cefálica (glándula cefálica). Esc.: $1 \mathrm{~mm}$.

Fig. 4. Nerthra, cephalic capsule (cephalic gland). Sca.: $1 \mathrm{~mm}$.

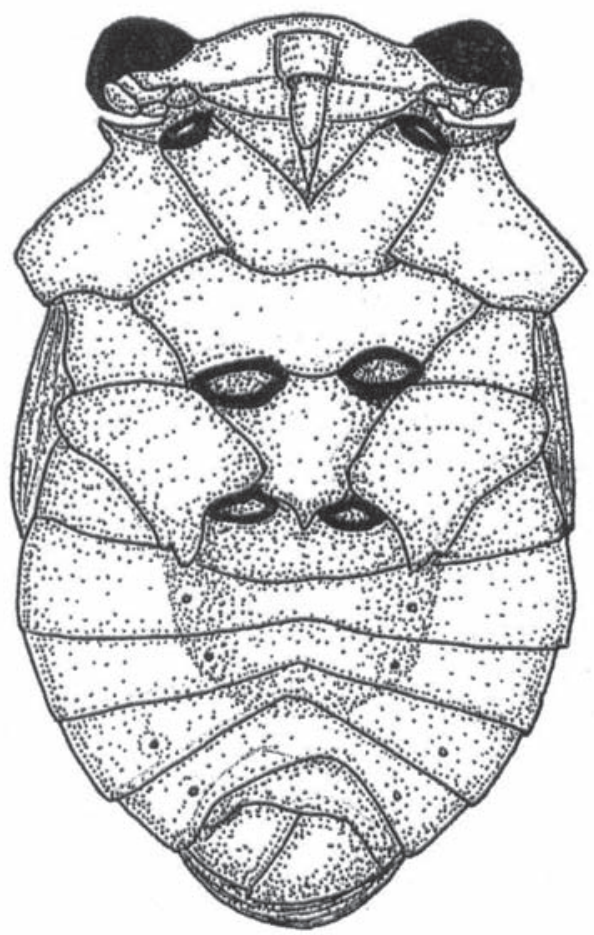

Fig. 3. Gelastocoris, espiráculos abdominales (esquema). Fig. 3. Gelastocoris, abdominal spiracles (sketch).

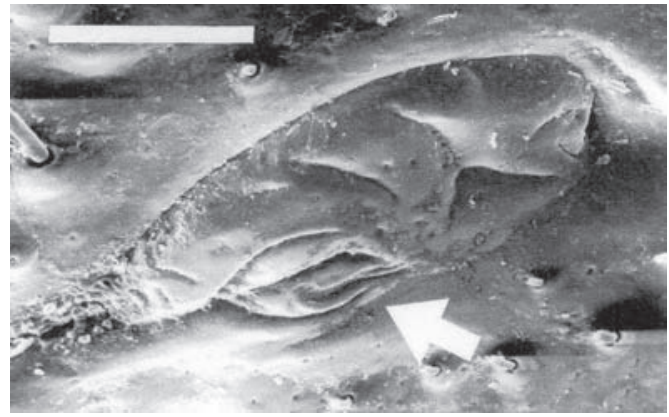

Fig. 5. Nerthra, abertura de la glándula cefálica. Esc.: $1 \mathrm{~mm}$. Fig. 5. Nerthra, cephalic gland opening. Sca.: $1 \mathrm{~mm}$. 


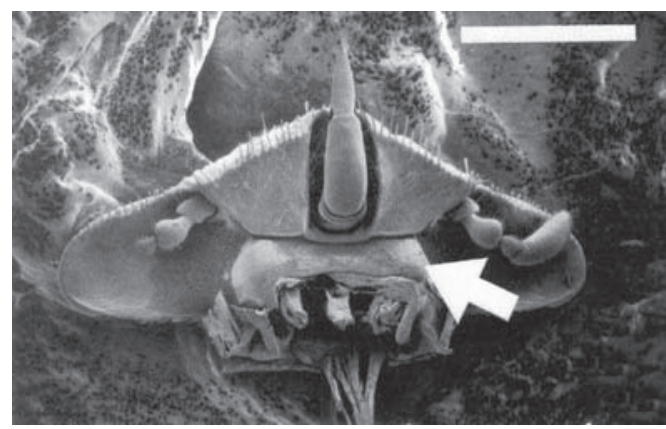

Fig. 6. Nerthra, cápsula cefálica (puente gular). Esc.: $1 \mathrm{~mm}$. Fig. 6. Nerthra, cephalic capsule (gular bridge). Sca.: $1 \mathrm{~mm}$.

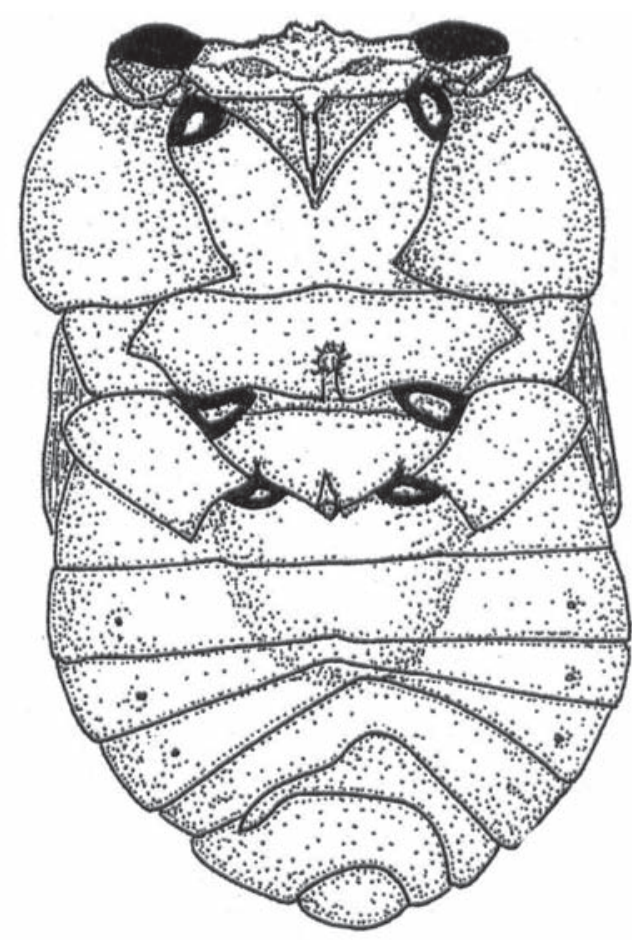

Fig. 7. Nerthra, espiráculos abdominales (esquema). Fig. 7. Nerthra, abdominal spiracles (sketch). y la concavidad en donde se sostiene la burbuja alcanza el III segmento abdominal (Fig. 7). El sexto esternito carece de espiráculos.

\section{AGRADECIMIENTOS}

Agradacemos a Axel O. Bachmann la lectura crítica del manuscrito y sus valiosas sugerencias y a Horacio D’Alessandro la digitalización de las imágenes. Este trabajo fue posible gracias al subsidio de la Universidad Nacional del Nordeste (Proyecto Iberá, Subproyecto Fauna del Iberá), Exp. N ${ }^{\circ}$ 01-20001-1452, Resol. 451/01.

\section{RESUMEN}

Se describen nuevos caracteres morfológicos diagnósticos que apoyan los argumentos utilizados por Todd, para separar las subfamilias Nerthrinae y Gelastocorinae (Gelastocoridae). Se describen e ilustran las glándulas cefálicas, la placa maxilar y la ubicación de los espiráculos abdominales.

Palabras clave: Heteroptera, Nerthrinae, Gelastocorinae, caracteres morfológicos.

\section{REFERENCIAS}

Lauck, D.R. \& W.G. Wheatcroft. 1958. Notes on a new habitat for Nerthra (Gelastocoridae-Hemiptera). Ent. News 69: 20.

Parsons, M.C. 1959. Skeleton and musculature of the head of Gelastocoris oculatus (Fabricius) (HemipteraHeteroptera). Bull. Mus. Comp. Zool. 122: 1-53.

Todd, E.L. 1955. A taxonomic revision of the family Gelastocoridae. Univ. Kansas Sc. Bull. 37: 277-475. 